\title{
Chemometric Analysis of Arbutin Derivatives from Paederia foetida and Vitis vinifera with Fourier Transform Infrared (FTIR)
}

\author{
Yusnita Rifai ${ }^{1, *}$, Mukhriani ${ }^{1}$, Yulia. Y. Djabir ${ }^{2}$, Gemini Alam ${ }^{3}$
}

Yusnita Rifai ${ }^{1, *}$, Mukhriani', Yulia. Y. Djabir ${ }^{2}$, Gemini Alam ${ }^{3}$

'Pharmaceutical Chemistry Laboratory, Faculty of Pharmacy, Hasanuddin University, Makassar 90245, INDONESIA.

${ }^{2}$ Clinical Chemistry Laboratory, Faculty of

Pharmacy, Hasanuddin University, Makassar 90245, INDONESIA.

${ }^{3}$ Phytochemistry Laboratory, Faculty of

Pharmacy, Hasanuddin University, Makassar 90245, INDONESIA.

Correspondence

\section{Yusnita Rifai}

Pharmaceutical Chemistry Laboratory,

Faculty of Pharmacy, Hasanuddin

University, Makassar 90245, INDONESIA.

E-mail: yusnita@fmipa.unhas.ac.id

History

- Submission Date: 23-1-2020;

- Review completed: 02-02-2020;

- Accepted Date: 11-02-2020.

DOI : 10.5530/pj.2020.12.67

Article Available online

http://www.phcogj.com/v12/i3

\section{Copyright}

(C) 2020 Phcogj.Com. This is an openaccess article distributed under the terms of the Creative Commons Attribution 4.0 International license.

\section{ABSTRACT}

Introduction: Paederia foetida and Vitis vinifera were reported to have antioxidant activities due to their polyphenolic phytochemical contents. Arbutin may be included as active compounds in the plants. The chemometric analysis is used to identify the similarity of functional groups found in arbutin and that are in Paederia foetida and Vitis vinifera. Materials and Method: The ethanol extracts of Paderia foetida and Vitis vinifera were subjected to compound partition and characterization. Then a liquid-liquid partition is carried out using n-hexan and water solvents, followed by ethyl acetate and water partitions. This procedure is carried out continuously until the top layer is cleared. Partitioned compounds were analyzed using FTIR spectroscopy to identify functional groups. Furthermore, it was analyzed using the chemometric method (Principal Component Analysis and Cluster Analysis). Results: From the results of FTIR spectroscopy, functional groups in Paederia foetida and Vitis vinifera were identical to functional groups found in arbutin. PCA Analysis was achieved using principal component accounting an eigenvelue about 99,3 \% of the total variance. Conclusions: CA analysis showed that compounds in Paederia foetida (Euclidean distance 0.537) and Vitis Vinifera (Euclidean distance 1.157) may be similar with arbutin.

Key words: Chemometrics, Paederia foetida, Vitis vinifera, Arbutin, PCA.

\section{INTRODUCTION}

Arbutin ( $\beta$-arbutin) is a natural whitening compound of glycosylated derivatives from hydroquinone as tyrosinase inhibitors. This compound can be obtained from Ericaceae (berberry, strawberry, huckleberry), Saxifragaceae, Asteraceae, Rosaceae, Lamiaceae, Apiaceae and is found in pears (Pyrus communis L.). The percentage of arbutin in plants varies greatly according to species (17\% in Arctostaphyllos uva ursi leaves, 5\% in majorama leaves). ${ }^{1}$

Several attempts have been made to investigate safe and effective tyrosinase inhibitors from both natural and synthetic compounds. ${ }^{2-4}$ Although there have been many studies and information about tyrosinase inhibitors, only few inhibitors can be applied due to their limitations in terms of cytotoxicity, selectivity and stability ${ }^{5,6}$ Skunk vine plant (Paederia foetida) and Grape (Vitis vinifera) are included.

Paederia foetida are one of the plants mentioned as having arbutin and have never isolated arbutin from these plants. This plant contains chemical compounds in the stem and leaves, namely asperuloside, deacetylasperuloside, scandoside, paederosid, paederosidic acid, gammasiitosterol, arbutin, oleanolic acid, and yawning oil. Grape plants (Vitis vinifera) have polyphenolic phytochemical content in the form of anthocyanins, tannins, flavonoids, resveratrol and phenolic acids. Polyphenols from grapes have a beneficial effect that can inhibit diseases such as heart disease, cancer, reduce plasma oxidation and slow aging.
In addition wine also has antioxidant, anticancer, anti-inflammatory, antiaging and antimicrobial effects. Another content contained in grape leaves is arbutin, mentioned that arbutin accumulates in grape leaves. ${ }^{7,8}$ It is necessary, therefore, to identify and characterize arbutin compounds contained in Paederia foetida and Vitis vinifera using FTIR spectrophotometers and chemometric analysis.

\section{MATERIAL AND METHODS}

\section{Materials}

Ethanol, ethyl acetate, chloroform, hexane, demineralized water and dimethyl sulfoxide (DMSO) were purchased from Merck. Indonesia. All chemicals and solvents were of analytical or pharmaceutical grade. Rotary Evaporatory (Buchi $\left.i^{\circ}\right)$ for vaporization of the solvents. IR data were collected on a IRPrestige- 21 using a $\mathrm{KBr}$ pellet.

\section{Extraction and partition}

Paederia foetida L. and Vitis vinifera were weighed and extracted separately by maceration method using ethanol. The dried samples were weighed and then put into the maceration container, then $96 \%$ ethanol was added to be completely submerged. The maceration container was closed and stored for $3 \times 24$ hours in a place that is protected from direct sunlight while stirring occasionally. Then extracts were filtered and separated from their pulps and filtrates. The ethanol filtrate obtained was then collected and evaporated using the rotary evaporator. The liquidliquid partition was then carried out with n-hexane and water solvents. The n-hexan filtrate was collected and evaporated to obtain the dried extract. Then the

Cite this article: Rifai $Y$, Mukhriani, Djabir YY, Alam G. Chemometric Analysis of Arbutin Derivatives from Paederia foetida and Vitis vinifera with Fourier Transform Infrared (FTIR) Pharmacog J. 2020;12(3):436-41. 
water phase is placed back into the separating funnel and repartitioned with ethyl acetate and water. This procedure was repeated 2 to 3 times.

\section{Identification of phenolic compounds}

To identify arbutin compounds includes polyphenol test, the extracts were added with $1 \% \mathrm{FeCl}_{3}$ solution. Results are shown in the form of green, red, purple, dark blue, blue, blackish blue, or blackish green. ${ }^{9}$

\section{Chemometric analysis}

The Minitab software (Release 18; Minitab, State College, PA) was used for chemometric analysis including principal component analysis (PCA) and cluster analysis (CA) for the absorbance of FTIR spectra.

\section{RESULTS AND DISCUSSION}

\section{FTIR Spectroscopy}

FTIR spectroscopy was used to determine the functional groups of a compound. From the IR spectra the arbutin compounds were identified as hydroxyl groups, $\mathrm{OH}$ stretching $\left(3380 \mathrm{~cm}^{-1}\right), \mathrm{CH}$ stretching $\left(2989,2929\right.$ and $\left.2881 \mathrm{~cm}^{-1}\right)$, and C-O stretching (1218 and $\left.1291 \mathrm{~cm}^{-1}\right)$.

The IR spectra of Paederia foetida leaf extract were identified for hydroxyl groups, $\mathrm{OH}$ stretching (3437 and $\left.3011 \mathrm{~cm}^{-1}\right), \mathrm{CH}$ stretching (2925 and $2854 \mathrm{~cm}^{-1}$ ), and C-O stretching $\left(1222\right.$ and $\left.1164 \mathrm{~cm}^{-1}\right)$. The IR spectra of Paederia foetida stem extract were identified for hydroxyl groups, $\mathrm{OH}$ stretching (3417 and $\left.3011 \mathrm{~cm}^{-1}\right), \mathrm{CH}$ stretching (2925 and $\left.2853 \mathrm{~cm}^{-1}\right)$, and C-O stretching $\left(1200 \mathrm{~cm}^{-1}\right)$.

For IR spectra of Vitis vinifera extract was identified for hydroxyl groups, $\mathrm{OH}$ stretching $\left(3407 \mathrm{~cm}^{-1}\right), \mathrm{CH}$ stretching $\left(2990 \mathrm{~cm}^{-1}\right)$, and C-O stretching $\left(1207 \mathrm{~cm}^{-1}\right)$.

\section{Principal component analysis}

Principal component analysis (PCA) is an unsupervised pattern recognition (Figures 1-4) method used in multivariate analysis. ${ }^{9}$ In this study, PCA was accomplished using FTIR spectra absorbances of 4 evaluated arbutin compounds at 4 frequencies as shown in Tables 1 and
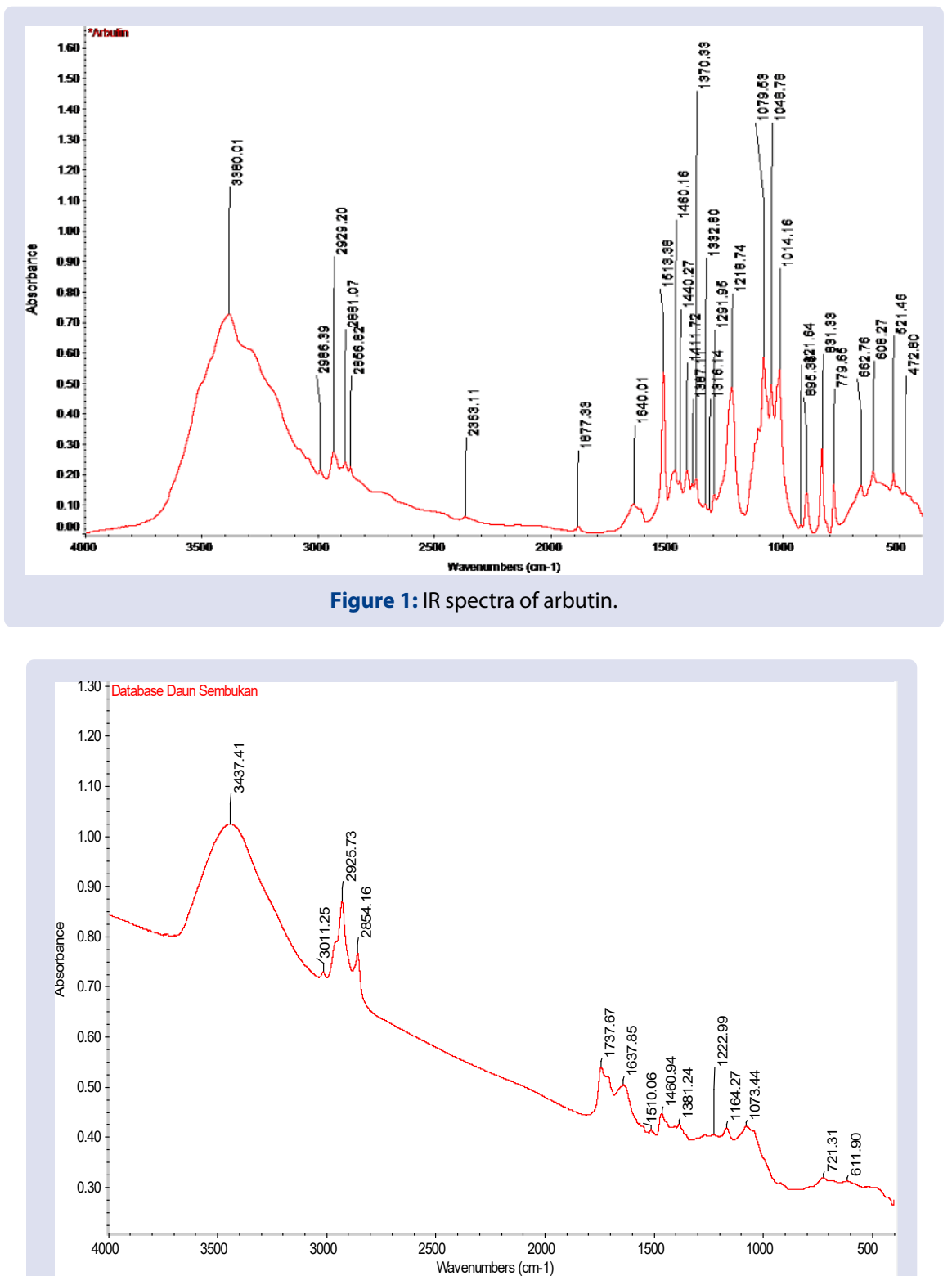

Figure 2: IR spectra of Paederia foetida leaf extracts. 


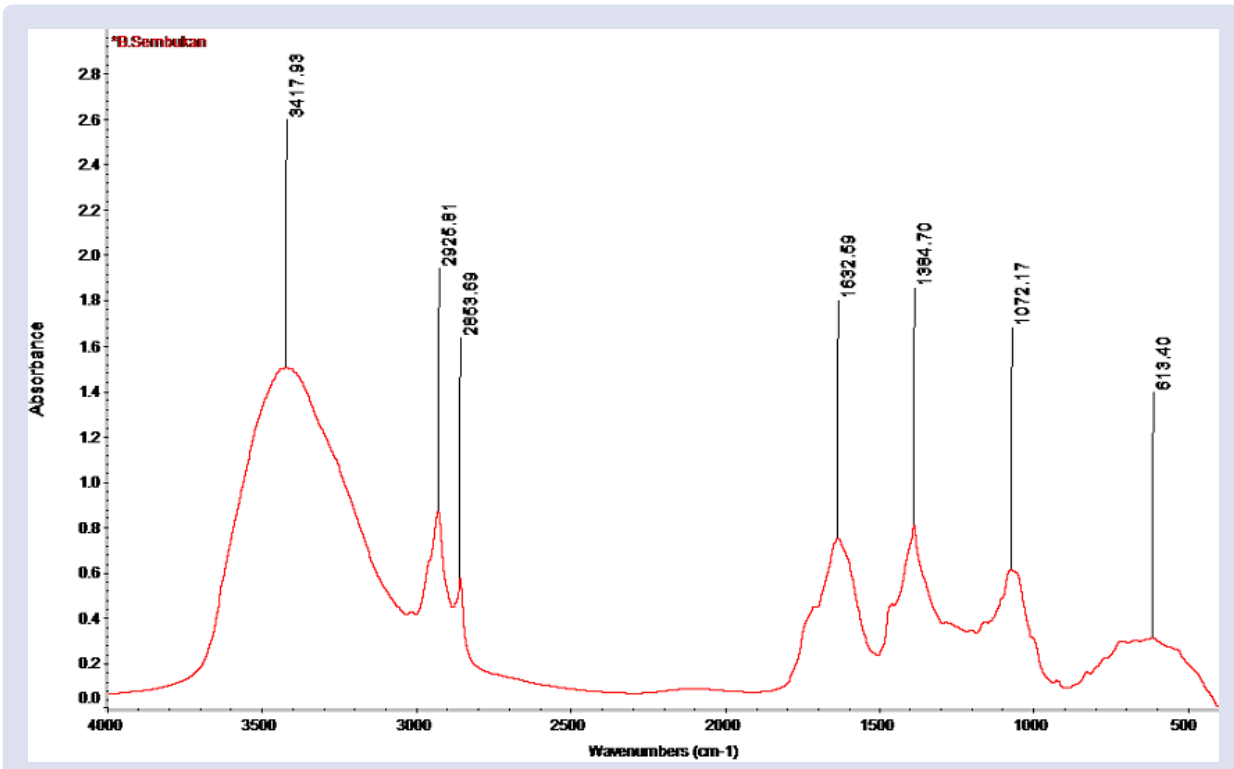

Figure 3: IR spectra of Paederia foetida stem extracts.

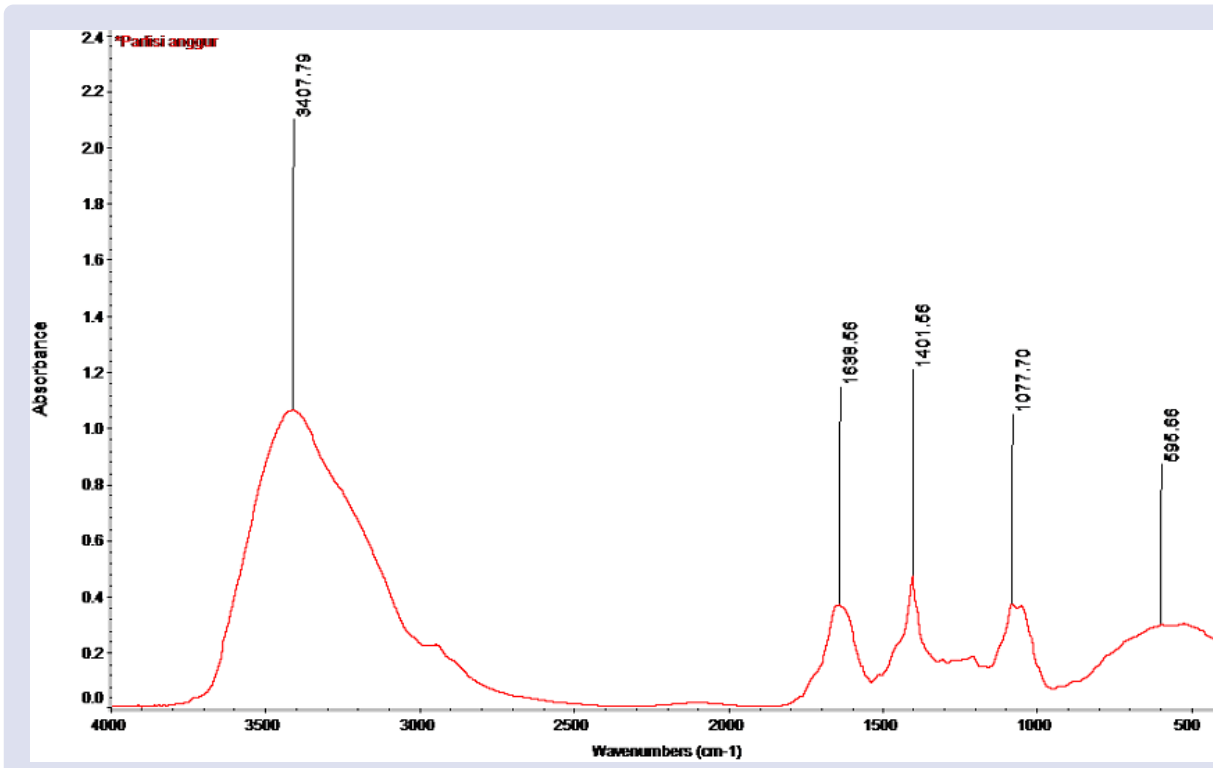

Figure 4: IR spectra of Vitis vinifera extracts.

2. PCA provided score and loading plot, showing the distribution of the samples and variables employed on the principal components (PCs), respectively. The score plot (Figure 5) exhibited patterns that may be correlated to sample characteristics. An eigenvalue of about $99.3 \%$ was achieved using two PCs. PC1 and PC2 described $95.3 \%$ and $4 \%$ of the variation, respectively. The study of the plote of loadings revealed distribution of variables and their correlations. From Figure 6, it is known that frequency regions at $1638.56 \mathrm{~cm}^{-1}$ and $3407.79 \mathrm{~cm}^{-1}$ make a larger contribution to the PCA model.

Cluster analysis (CA) is an algorithmic to construct hierarchy of clusters to assign observations to groups who are in the same class. In CA, clusters are visualized in dendogram graphs. Figure 7 shows a dendogram which is divided into two clusters: arbutin and Paederia foetida leaf with Euclidean distance 0.537, followed by Paederia foetida stem and Vitis vinifera.with Euclidean distance 1.157. In this study, CA results are in accordance with PCA results. They are in the same classes.
Table 1: IR spectra of compounds.

\begin{tabular}{|c|c|c|c|c|}
\hline \multicolumn{4}{|c|}{ Wavenumbers $\left(\mathrm{cm}^{-1}\right)$} & \multirow{2}{*}{$\begin{array}{c}\text { Functional } \\
\text { Group }\end{array}$} \\
\hline Arbutin & $\begin{array}{c}\text { Paederia } \\
\text { foetida leaf }\end{array}$ & $\begin{array}{c}\text { Paederia } \\
\text { foetida stem }\end{array}$ & Vitis vinifera & \\
\hline 3380 & 3437,3011 & 3417,3011 & 3407 & OH stretching \\
\hline $\begin{array}{c}2986, \\
2929,2881\end{array}$ & 2925,2854 & 2925,2853 & 2990 & $\mathrm{CH}$ stretching \\
\hline 1218,1291 & 1222,1164 & 1200 & 1207 & C-O streching \\
\hline
\end{tabular}

Table 2: Peak intensities (absorbances) of compounds.

\begin{tabular}{cccccc}
\hline \multirow{2}{*}{ No } & \multirow{3}{*}{ Compounds } & \multicolumn{4}{c}{ Frequency } \\
\cline { 3 - 6 } & & 611.9 & 1077.7 & 1638.56 & 3407.79 \\
\hline 1 & Arbutin & -1.449 & -1.131 & -1.654 & -0.931 \\
2 & Vitis vinifera & -1.214 & -1.052 & -0.937 & 0.018 \\
3 & Paederia foetida leaf & -1.69 & -1.582 & -1.498 & -0.978 \\
4 & Paederia foetida stem & -0.693 & -0.413 & -0.29 & 0.508 \\
\hline
\end{tabular}




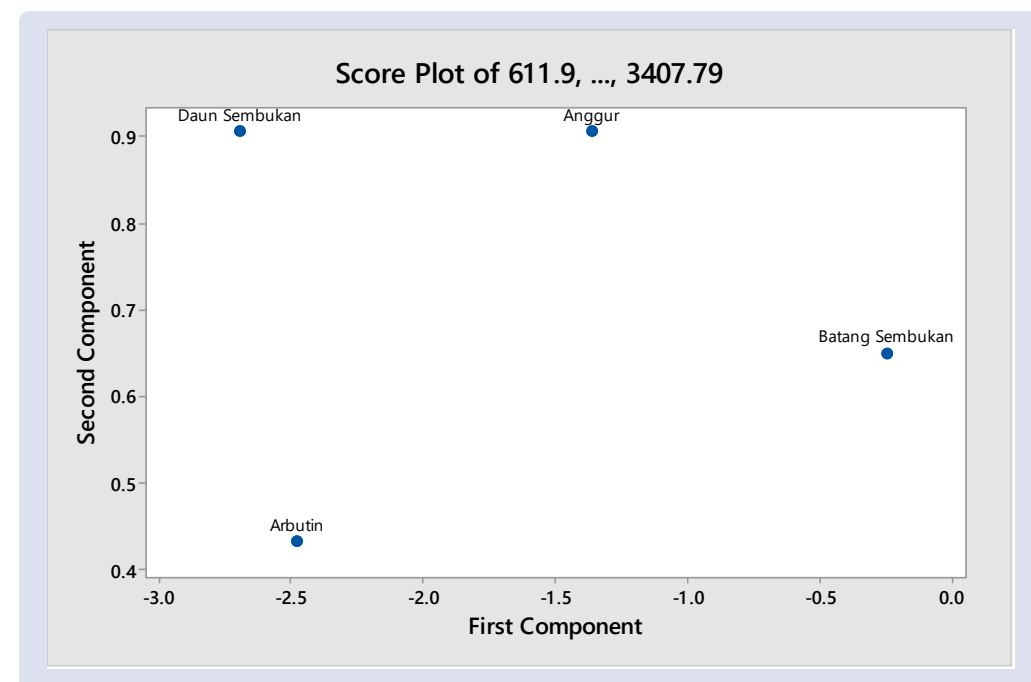

Figure 5: Principal component analysis score plot.

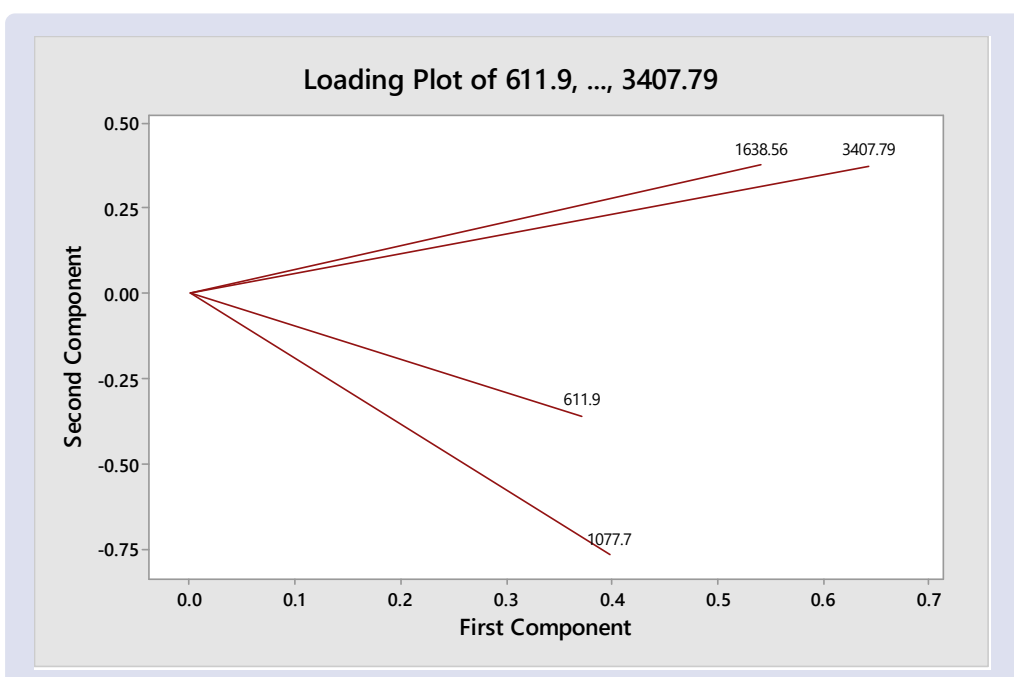

Figure 6: Principal component analysis loading plot of PC1 and PC2 Cluster Analysis.

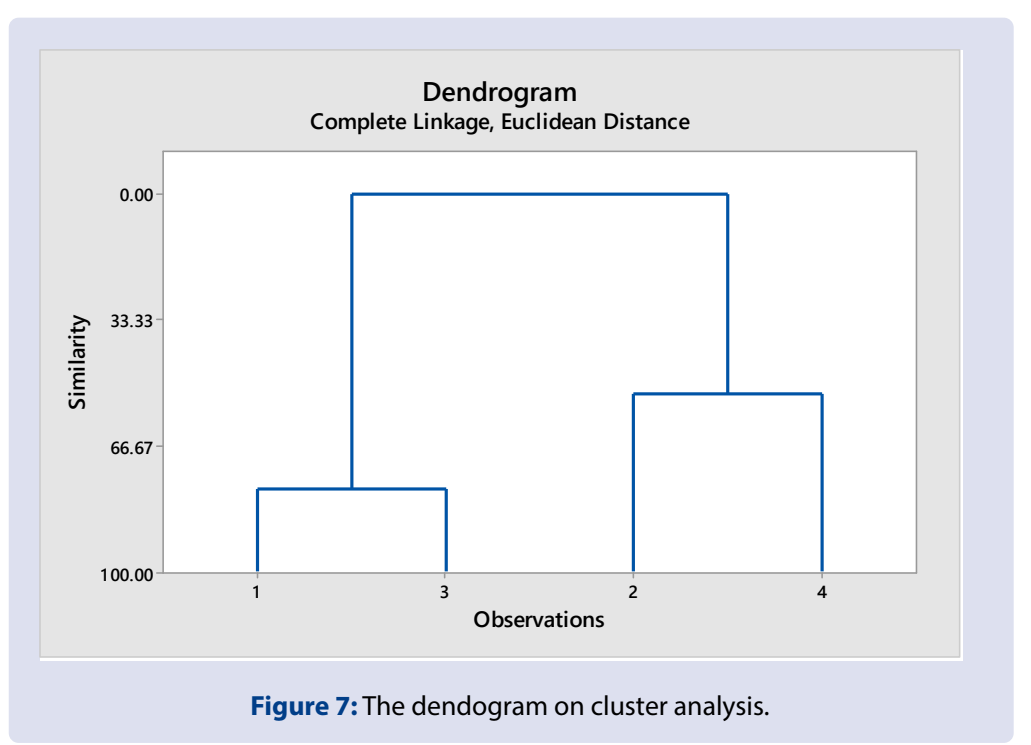




\section{CONCLUSIONS}

In this work, we partitioned the extract of Paederia foetida and Vitis vinifera extracts. Furthermore, we combined FTIR spectroscopy with chemometric analysis to exhibit the similarity in their physic and chemical properties. CA analysis showed that arbutin derivatives may be included in Paederia foetida (Euclidean distance 0.537) and Vitis Vinifera (Euclidean distance 1.157).

\section{ACKNOWLEDGEMENTS}

This work was supported by Ministry of Research, Technology, and Higher Education of the Republic of Indonesia. We are grateful to Faculty of Pharmacy Hasanuddin University.

\section{REFERENCES}

1. Ley JP, Bertram HJ. Hydroxy- or Methoxy-Substituted Benzaldoximes and Benzaldehyde-O-alkyloximes as Tyrosinase Inhibitors. Bioorganic Med Chem 2001:9(7):1879-85.
2. Um SJ, Park MS, Park SH, Han HS, Kwon YJ, Sin HS. Synthesis of new glycyrrhetinic acid (GA) derivatives and their effects on tyrosinase activity. Bioorganic Med Chem. 2003;11(24):5345-52.

3. Seo SY, Sharma VK, Sharma N. Mushroom Tyrosinase: Recent Prospects. J Agr Food Chem. 2003;5(10):2837-53.

4. Karioti A, Protopappa A, Megolaus N, Skaltsa H. Identification of tyrosinase inhibitors from Marrubium velutinum and Marrubium cylleneum. Bioorganic Med Chem. 2007;15(7):2708-14.

5. Satooka H, Kubo I. Effects of Thymol on B16-F10 Melanoma Cells. J Agric Food Chem. 2012;60(10):2746-52.

6. Xia EQ, Deng GF, Guo YJ, Li HB. Biological Activities of Polyphenols from Grapes. Int J of Mol Sci. 2010;11(2):622-46.

7. Rossow GC, Orchard BA, Suklje K, Smith JP, Barril P, Deloira A, Holzapfe BP. Vitis vinifera root and leaf metabolic composition during fruit maturation: implications of defoliation. Physiol Plant. 2017;161(4):434-50.

8. Farrés-Cebrián M, Seró R, Saurina J, Núñez O. HPLC-UV Polyphenolic Profiles in the Classification of Olive Oils and Other Vegetable Oils via Principal Component Analysis. Separations. 2016;3(4):33.

9. Cebi N, Yilmaz MT, Sagdic O. A rapid ATR-FTIR spectroscopic method for detection of sibutramine adulteration in tea and coffee based on hierarchical cluster and principal component analyses. Food Chem. 2017:229(15):517-26.

\section{GRAPHICAL ABSTRACT}

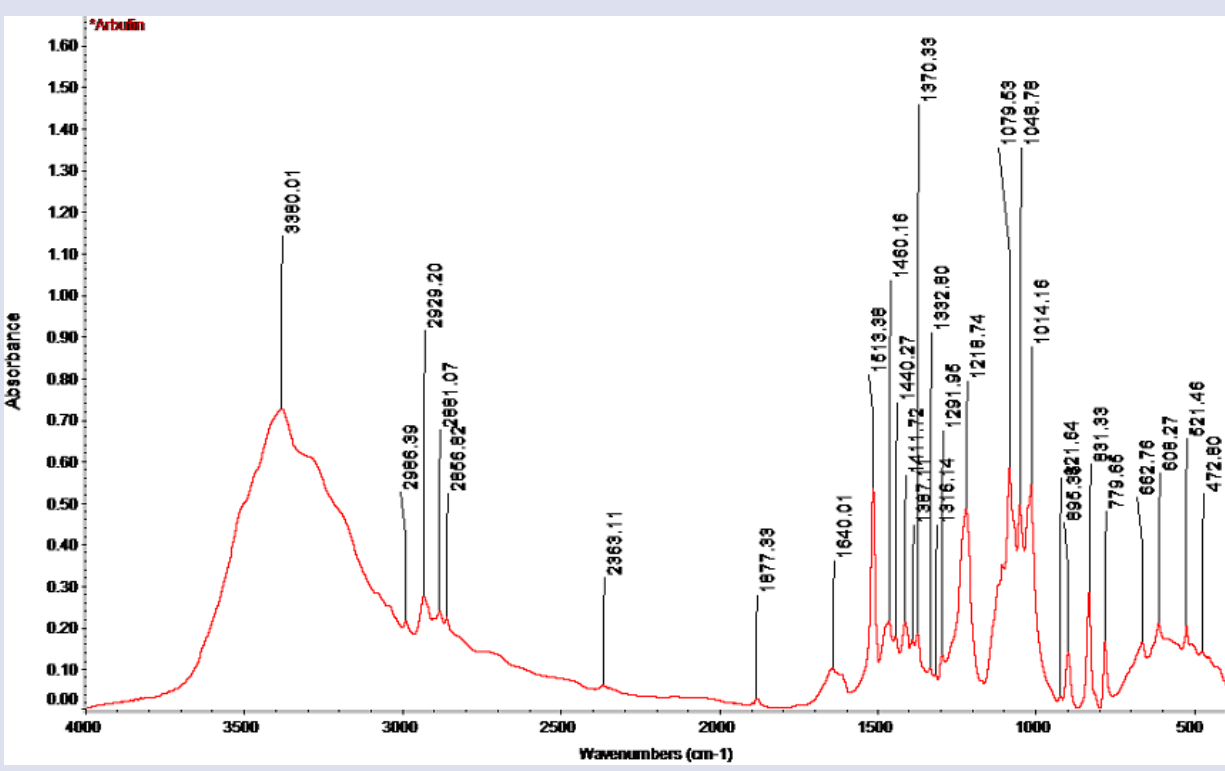

\section{SUMMARY}

Arbutin compounds contained in Paederia foetida and Vitis vinifera were classified on the basis of their infrared spectra by pattern recognition method in chemometric analysis.

\section{ABOUT AUTHORS}

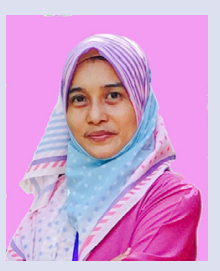

Yusnita Rifai was honored of Endeavour Post-Doctoral Fellowship 2014 to continue her post-doctoral study at the University of Newcastle Australia. Her research interests lie in the area of drug discovery, including drug synthesis. There are some of research in medicinal chemistry that obtained recognitions, one of them is from Timmerman Award in 2013.

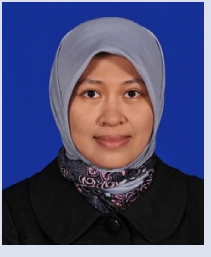

Mukhriani is a postgraduate student at the Faculty of Pharmacy, Hasanuddin University. She is working on the research related to the chemical screening of naturally occurring arbutin from various Indonesian plants under the supervision of Yusnita Rifai. 


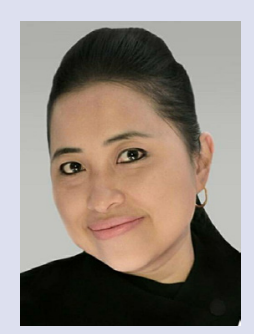

Yulia Y Djabir is the head of clinical pharmacy laboratory at Faculty of Pharmacy Hasanuddin University. Her research interest is in the field of pharmacology and toxicology of synthetic and herbal medicine. She is also involved in some clinical studies regarding the safety use of drugs.

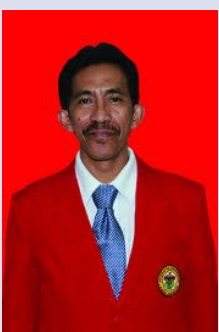

Gemini Alam is the head of phytochemistry laboratory at Faculty of Pharmacy Hasanuddin University. He is a professor in the field of natural products. His research is focused on the isolation, analysis, and bioactivity of natural products. Since 2017 he has been working on chemical screening using chemometric analysis.

Cite this article: RifaiY, Mukhriani, Djabir YY, Alam G. Chemometric Analysis of Arbutin Derivatives from Paederia foetida and Vitis vinifera with Fourier Transform Infrared (FTIR).Pharmacog J. 2020;12(3):436-41. 